\title{
Trade Restrictiveness Benchmarks
}

\author{
James E. Anderson Boston College
}

June 1995

\begin{abstract}
This paper provides benchmarks of trade restrictiveness and year-on-year changes in trade restrictiveness using the Trade Restrictiveness Index. These benchmark measures stand in sharp contrast to standard measures. For a 28 country sample the TRI is used to compare trade policy in a recent year with free trade. Trade weighted average tariffs substantially underestimate restrictiveness measured by the 'uniform tariff equivalent' (the inverse of the TRI minus one), with the degree of underestimate positively correlated with the dispersion of the tariff structure. The rank correlation of the 'uniform tariff equivalent' and the average tariff in the sample is high, but the error implied by using the average tariff instead of the uniform tariff equivalent is substantial and variable. For a 7 case sample, year-on-year recent changes in trade policy are evaluated with the TRI and with standard measures. Here, the correlation of the TRI and changes in the standard measures is close to zero, essentially because tariff means and variances often do not move together. These conclusions appear to be robust with respect to missing data problems. The magnitude of the TRI is not very sensitive to elasticity of substitution variation, but is sensitive to the assumptions used to treat NTBs.

JEL Classifications F10, D58
\end{abstract}

Presented at the Conference on Recent Developments in International Economics, Aix en Provence, June 1995. Funding from the World Bank is gratefully acknowledged. 
Policy analysis frequently requires indices of taxation or regulation. Average tax rate comparisons are common across US state and local jurisdictions, tax equivalents of environmental regulations are often compared internationally and intertemporally, and trade policy comparisons are widespread. All such indices are without theoretical foundation. Anderson and Neary (1995) develop a theoretically consistent index of trade policy for both tariff and nontariff barriers, the Trade Restrictiveness Index (TRI). The policy index problem and its solution apply to fiscal and regulatory index numbers more generally, but are left for future development. Here, as an example of the payoff to such methods, the TRI is applied to trade policy comparisons. It turns out to make a great difference.

Two examples of the practical problems due to the lack of theoretically based index numbers of trade policy stand out. First, the link between openness and growth can't be reliably examined without such indices (Edwards, 1993), yet investigators have proceeded with such admittedly unsatisfactory measures as trade weighted average tariffs. Second, the World Bank routinely uses tariff mean and dispersion indices in the evaluation of loan conditionality despite qualms about their relevance. The TRI (Anderson and Neary, 1995) provides a satisfactory measure for such purposes. The TRI is equal to the uniform deflator which, applied to domestic prices distorted by trade policy, is just as inefficient as the given trade distortion structure. The TRI extends from tariffs only to include both tariffs and quotas and to include the trade restrictiveness impact of domestic measures such as production subsidies (Anderson, Bannister and Neary, 1995).

The purpose of this study is to use the TRI to provide a set of benchmark measures of overall recent trade policy and its evolution for a country cross section. Systematic detailed panel data for trade policies is not available 1 , so the evidence presented here is necessarily rather modest in scope. Nevertheless, the TRI measures in this paper can be

\footnotetext{
${ }^{1}$ Detailed data for trade flows, tariffs and nontariff barriers is needed on a comparable classification basis. This requires the detailed data and a concordance effort. Very recently, the TRAINS data set of the UNCTAD provides such information for current years. In principle a major data collection project could provide a panel of such information for the postwar era.
} 
used as reference points in evaluating the large body of work on openness and growth on the one hand and the analysis of trade policy evolution in developing countries on the other hand. Two sorts of measures are presented. First, the TRI is calculated based on comparing the actual policy of a recent year to the alternative policy of free trade in a 28 country cross section. The sample includes both developed and developing countries, and high and low protection countries. Second, the TRI is used to evaluate 7 cases of year-onyear changes in trade policy of a group of developing countries. An evaluation of yearly trade policy changes is part of the routine for loan conditionality in the World Bank's Structural Adjustment Loan program.

With the benchmark measures in hand it is useful to compare the TRI measure of nations' trade restrictiveness with the standard atheoretic measures such as the trade weighted average tariff and coefficient of variation of tariffs. The results show that standard measures are very significantly misleading about the trade restrictiveness of actual policies, both relative to free trade and especially relative to previous years' trade policies. As for the free trade comparison, the TRI is used to compare trade policy in a recent year with free trade for a 28 country sample. Trade weighted average tariffs substantially underestimate restrictiveness measured by the 'uniform tariff equivalent' (the inverse of the TRI minus one). ${ }^{2}$ The average amount of underestimation is about $50 \%$ of the average tariff, but there is a large amount of dispersion in the 'error'. Nevertheless, the rank correlation of the 'uniform tariff equivalent' and the average tariff in the sample is high. Interestingly, the degree of underestimate is positively correlated with the dispersion of the tariff structure, which weakly validates the atheoretic preoccupation of many applied economists with dispersion as well as mean of tariff schedules. As for comparisons to other years' trade policies, year-on-year recent changes in trade policy are evaluated with the TRI and with standard measures for 7 cases. Here, the correlation of the TRI and

\footnotetext{
${ }^{2}$ The TRI is a price deflator, hence like the inverse of a tariff factor. The quotation marks about 'uniform tariff equivalent' signify that in many of the most realistic cases, there is no exact uniform tariff equivalent.
} 
changes in the standard measures is close to zero, essentially because tariff means and variances often do not move together in yearly changes. ${ }^{3}$ A third purpose of the paper is to illustrate how TRI measures may make a difference in studies of the linkage of trade, trade policy and economic growth.

The basis of the calculations is a simple Computable General Equilibrium (CGE) model which imposes extreme simplification of the production structure while preserving the fine structure of protection in the model. The simplicity in production is imposed to make feasible the calculation of almost any country's TRI without requiring detailed production data of the kind needed in typical CGE models. The CGE model is assumed to be qualitatively identical across countries, including the same elasticity parameters, while differing in share parameters given by the data.

The treatment of nontariff barriers (NTBs) is critical to the evaluation of trade distortions. All effective NTBs are treated as binding quotast. The TRI converts quotas to tariff equivalents, with tariff equivalence defined as domestic price equivalence. The implied change in domestic prices is calculated when restricted quantities change, which yields a kind of terms of trade effect. In the evaluation of year-on-year changes, information on quota premia (which is generally missing) is not needed under the assumption that at the margin all quota rent beyond that retained by tariffs is lost to rentseeking or to foreigners. In the evaluation of the hypothetical move to free trade, the missing quota premia problem means that free trade prices are unknown, so even more

\footnotetext{
${ }^{3}$ Other complementary studies include several time series comparisons of policy in narrowly defined categories: cheese in the US (Anderson, 1991), agriculture in Mexico (Anderson, Bannister and Neary, 1994), and Multi-Fibre Arrangement goods for the US and its bilaterally constrained trading partners (Anderson and Neary, 1994).

${ }^{4}$ The effectiveness of nontariff barriers is a matter of judgment. This study applied a conservative method which treats many nontariff barriers as nonbinding. First, only 'hard core' nontariff barriers were considered. Second, in the unavoidable aggregation to the 4 digit HS code level from more detailed data which could not be concorded element by element, a 4 digit HS code import was counted as subject to nontariff barrier only if more than $75 \%$ of its elements were subject to nontariff barriers.

5 This definition is used rather than an equivalent price differential because with less than full rent retention there is no exact link between international price differentials and tariffs.
} 
extreme assumptions must be used to proceed. Three expedients are used here. First, all NTBs are assumed away at the margin by supposing that they fail to bind. Second, the binding NTBs are assumed to cause price differentials which are captured in an assumed $10 \%$ uniform quota premium, in addition to the differential due to tariffs on quotaconstrained goods. The uniform tariff equivalent is allowed to capture formerly lost quota rent. Third, free trade is assumed to cause a uniform $10 \%$ rise in restricted quantities, and the uniform equivalent restriction is assumed to tighten quotas such that domestic prices rise uniformly, all rent above the rent-retaining tariff level being lost. The results of the first two approaches differ somewhat while the third differs significantly. Sensitivity analysis also reveals that the size of the assumed uniform premium or assumed uniform quantity change matters . All these results underline the importance of doing as good a job as possible on nontariff barrier information.

Beyond the difficulties created by missing information about NTBs, several other important limitations to the study should be noted. The TRI is calculated here using a highly specialized CGE model. Sensitivity analysis reveals that the ranking of countries' trade restrictiveness is not very sensitive to variation in the elasticity parameters. However, the effect of different CGE model specifications on the ranking of trade restrictiveness awaits further work. Finally, an important implication of this research is that aggregation of trade distortions matters. The model which implements the TRI here permits theoretically consistent aggregation from about 1200 lines of trade and trade distortion data, below which missing information necessitated atheoretic aggregation using trade weights. ${ }^{6}$ A finer classification system would permit consistent aggregation from 'primitives' and might alter the ranking of countries by trade restrictiveness.

Limitations aside, this study demonstrates that it is feasible to do a great deal better than previously possible in calculating index numbers of trade policy. It should similarly

\footnotetext{
${ }^{6}$ The problem is that trade flows, tariffs and nontariff barriers are all classified with different systems, and concording these at the finest level of classification of each is impossible.
} 
be possible to do better with index numbers of other policies. Many of the methods for the analysis of tariff policy carry straight over to domestic fiscal policy, with income and commodity taxation replacing tariffs. In environmental policy, the instruments are often quotas, sometimes marketable, and here the methods developed for trade quotas should apply.

\section{The Model}

The model will be described in stages. First an abstract general equilibrium model is used to derive the TRI. Second, the general equilibrium model is operationalized as a simple CES/CET form. Third comes a formal description of the various treatments of NTBs. 


\section{A. The basic model of the TRI}

The basic idea of the Trade Restrictiveness Index is to combine a version of index number theory with an appropriate general equilibrium model of trade distortions. The version of index number theory we use is most simply seen by considering the true costof-living index. The cost-of-living deflator is defined as the uniform deflator $\mathrm{d}$ which, applied to the new prices, allows the old level of utility to be maintained with the old level of expenditure: $\mathrm{d}\left(\pi^{1}, \mathrm{u}^{0}, \pi^{0}\right)=\left\{\mathrm{d} \mid \mathrm{e}\left(\pi^{1} / \mathrm{d}, \mathrm{u}^{0}\right)=\mathrm{e}\left(\pi^{0}, \mathrm{u}^{0}\right)\right\}$, where $\pi^{1}$ is the new price vector, $\pi^{0}$ is the old price vector, $\mathrm{u}^{0}$ is the old level of utility and $\mathrm{e}$ is the expenditure function. The TRI is defined as a deflator $\Delta$ which deflates distorted traded goods prices at their new level so as to maintain the old level of utility for the representative consumer while respecting general equilibrium.

The general equilibrium analogy to the consumer's expenditure function is the balance of trade function. Following Anderson and Neary $(1992,1994)$ we develop it briefly here. The basic building block is the trade expenditure function $\mathrm{E}(\mathrm{p} \pi, \mathrm{u}, \gamma)$, where $\mathrm{p}$ is the domestic price of a set of quota constrained imports, $\pi$ is the domestic price of a set of tariff constrained imports, $\mathrm{u}$ is utility level of the representative consumer and $\gamma$ is a vector of exogenous shift parameters. E gives the net value of expenditure on all traded goods in terms of domestic prices, and is the difference between the consumer's expenditure and the Gross Domestic Product (GDP). In the background, there is a numeraire untaxed traded good, there may be many other untaxed traded goods, and the nontraded goods and factors have equilibrium prices which are functions of the exogenous variables $(p, \pi, u, \gamma)$. The levels of $p$ and $\pi$ are set by a combination of the small country assumption and the trade policy.

The undistorted balance of trade function is formed assuming an unlimited amount of the quota-constrained goods can be purchased at price p: i.e., there is no binding quota. The balance of trade is equal to the difference between $\mathrm{E}$ and the net revenue from trade distortions. It is defined by: 


$$
\mathrm{B}(\mathrm{p}, \pi, \mathrm{u}, \gamma)=\mathrm{E}(\mathrm{p}, \pi, \mathrm{u}, \gamma)-\left(\pi-\pi^{*}\right)^{\prime} \mathrm{E}_{\pi}-\mathrm{t}^{\prime} \mathrm{E}_{\mathrm{p}}
$$

where $\pi^{*}$ is the foreign price vector of the tariff-ridden unconstrained goods, $\left(\pi-\pi^{*}\right)^{\prime}$ is the tariff vector for these goods and $\mathrm{t} q$ is the tariff vector of quota-constrained goods. Using Shephard's Lemma, $\mathrm{E}_{\pi}$ is the trade vector of unconstrained goods and $\mathrm{E}_{\mathrm{p}}$ is equal to the actual quota provided $\mathrm{p}$ is set at the proper level. We distinguish the two tariff vectors because $\mathrm{t} \mathrm{q}$ is a rent-retaining tariff which is non-distortionary at the margin, not necessarily equal to $\mathrm{p}-\mathrm{p}^{*}$. The setup in equation (1) assumes that all quota rent other than that retained in $\mathrm{tq}^{\prime} \mathrm{E}_{\mathrm{p}}$ is lost to foreigners or to rent-seeking. This extreme simplification of the rent sharing story is imposed to get around the problem of missing data on the actual rentsharing mechanism, reflected especially in the absence of license price data.

The distorted balance of trade function makes explicit the binding nature of the underlying quota vector q. Following Anderson and Neary (1992) we define the distorted trade expenditure function as the value of expenditure on unconstrained goods needed to support $\mathrm{u}$. Formally it is defined by:

$$
\widetilde{\mathrm{E}}(\mathrm{q}, \pi . \mathrm{u}, \gamma)=\max _{\mathrm{p}}\left\{\mathrm{E}(\mathrm{p}, \pi, \mathrm{u}, \gamma)-\mathrm{p}^{\prime} \mathrm{q}\right\} .
$$

$\widetilde{\mathrm{E}}$ inherits the properties of $\mathrm{E}$ so that the unconstrained trade vector is $\widetilde{\mathrm{E}}_{\pi}$, while by the envelope theorem applied to (2), the domestic price of quota-constrained goods is equal to $-\widetilde{\mathrm{E}}_{\mathrm{q}}$. The distorted balance of trade function is now defined as:

$$
\widetilde{\mathrm{B}}(\mathrm{q}, \pi, \mathrm{u}, \gamma)=\widetilde{\mathrm{E}}(\mathrm{q}, \pi, \mathrm{u}, \gamma)-\widetilde{\mathrm{E}}_{\mathrm{q}} \mathrm{q}^{\mathrm{q}}-\left(\pi-\pi^{*}\right)^{\prime} \widetilde{\mathrm{E}}_{\pi}-\mathrm{tq}^{\prime} \mathrm{q} \text {. }
$$

The connection between (1) and (3) is that for (1) to reflect the general equilibrium, p must be equal to $-\widetilde{\mathrm{E}}_{\mathrm{q}}(\mathrm{q}, \pi, \mathrm{u}, \gamma)$.

The TRI converts a set of new trade instruments $\mathrm{q}^{1}, \pi^{1}$ into a scalar index which is a uniform tariff and tariff equivalent deflator designed to preserve $\mathrm{u}^{0}$ and satisfy the general equilibrium budget constraint. Moving from (3) back to (1), the domestic price of the quota-constrained good must be

(4) $\tilde{\mathrm{p}} \quad=\quad-\widetilde{\mathrm{E}}_{\mathrm{q}}\left(\mathrm{q}^{1}, \pi^{1}, \mathrm{u}^{0}, \gamma^{0}\right)$.

Then the TRI is defined by: 


$$
\Delta\left(\mathrm{q}^{1}, \pi^{1}, \mathrm{u}^{0}, \gamma^{0} ; \mathrm{q}^{0}, \pi^{0}\right)=\quad\left\{\Delta \mid \mathrm{B}\left(\tilde{\mathrm{p}} / \Delta, \pi^{1} / \Delta, \mathrm{u}^{0}, \gamma^{0}\right)=\widetilde{\mathrm{B}}\left(\mathrm{q}^{0}, \pi^{0}, \mathrm{u}^{0}, \gamma^{0}\right)\right\} .
$$

Note the parallel of the TRI defined by (5) with the cost-of-living index: $\Delta$ deflates the new distorted prices so as to preserve real income $\mathrm{u}^{0}$ while expending no more than in the initial situation. Now consider the interpretation of $\Delta$. For a cut in tariffs and a quota expansion such that $\mathrm{p}$ and $\pi$ fall uniformly, there is no ambiguity in any restrictiveness index: each element of the price vector stands for all others and $\Delta$ will be less than one by the percentage drop in distorted prices. The power of the TRI is that this uniform tariff equivalence interpretation holds for non-uniform changes in $\mathrm{p}$ and $\pi$; its percentage change gives the uniform tariff surcharge which is equivalent to the actual change $\widetilde{p}, \pi^{1}$.

An important interpretation of the TRI arises when the new situation is free trade. At free trade, $\pi^{1}$ is equal to $\pi^{*}$ and $\tilde{p}$ is equal to $\mathrm{p}^{*}$. If the fixed rent retaining tariff $t \mathrm{t}$ is replaced with a full rent retaining tariff equal to $\widetilde{\mathrm{p}}-\mathrm{p}^{*}$, there is complete symmetry in the treatment of constrained and unconstrained goods, and the calculated value of $\Delta$ is equal to the inverse of one plus the uniform tariff which destroys as much welfare as the initial trade distortions. If the rent-retaining tariff remains fixed at $\mathfrak{t}, \Delta$ is equal to the inverse of one plus the uniform tariff which rebates to foreigners all revenue on quota-constrained goods above tq' $\mathrm{q}$ and destroys as much welfare as the initial distortions. See Anderson and Neary (1994) for details.

\section{B. Operationalizing the general equilibrium model}

The general equilibrium application reported below uses a simple Computable General Equilibrium (CGE) model. In contrast with standard CGE models, it greatly reduces the complexity of the production structure while preserving a high degree of disaggregation in detailed trade distortions. (Typical CGE models allow for a few dozen sectors but use trade weighted average tariffs and tariff equivalents to summarize trade 
policy for each sector. $)^{7}$ The aggregation in production is for practical reasons, to allow a large number of countries to be quickly analyzed.

The economy produces two final composite goods, an exportable not consumed at home and a nontraded good. That is, the Armington assumption is applied to both imports and exports. The rationale for the Armington assumption of no domestic consumption of the export is that packaging, safety and other requirements differentiate it from home goods, while the absence of domestic production of imports is due to other dimensions of product differentiation.

Exports and nontraded goods are jointly produced with a Constant Elasticity of Transformation (CET) production function. The inputs include a bundle of non-traded factors of production in fixed supply, hence reducible to a single input; a vector of imported inputs subject to binding quota constraints; and a vector of imported inputs subject to tariffs but not subject to quotas. A Constant Elasticity of Substitution (CES) production function relates the inputs to the joint output. The technology exhibits constant returns to scale.

As for consumption, the representative consumer's tastes are represented by a CES expenditure function. The final goods consumed are a vector of final imports subject to tariff but not quota, a vector of final imports subject to binding quota constraints, and the nontraded good.

All tariff revenue is assumed to be redistributed to the representative consumer. This includes tariff revenue collected on quota-constrained goods, where it serves to secure a portion of the quota rents. The economy is assumed to lose all quota rent other than that retained by tariffs: either to rent-seeking or to foreigners via the bargaining power they may have in narrow product lines. All nontariff barriers are assumed to be quotas (or ignored

\footnotetext{
${ }^{7}$ Cox and Harris (1985) is notable for exact aggregation using a Cobb-Douglas specification for each sub-expenditure or cost function. Even so, Cox and Harris fail to adequately treat nontariff distortions, simply assigning a fixed tariff equivalent for each quota constrained good.
} 
as nonbinding). ${ }^{8} \quad$ The economy is assumed to be 'small', facing fixed international prices. In general equilibrium, the equilibrium level of real income (utility) of the consumer is determined by the balance of trade constraint, simultaneously with market clearance for nontraded goods and factors.

The CES/CET version of the general distorted trade model set out above will now be presented. Gross Domestic Product (GDP) is equal to the value of the nontraded good plus the export good (which is the numeraire) less the domestic value of imported inputs. Consumer expenditure is equal to the value of the nontraded good plus the domestic value of the final imports. Starting with the standard expenditure function, the distorted expenditure function is the minimum expenditure on unconstrained goods required to support a given real income $\mathrm{u}$ with prices for unconstrained final imports $\pi^{\mathrm{F}}$, nontraded good price $h$ and quotas $\mathrm{q}^{\mathrm{F}}$. Similarly the distorted GDP function is the maximum value of GDP possible with imported input (materials) prices $\pi^{\mathrm{M}}$, nontraded good price $\mathrm{h}$, and input quotas $\mathrm{q}^{\mathrm{M}}$, and shift parameters $\gamma$. The distorted trade expenditure function is the difference between the distorted expenditure and GDP functions. Let the distorted consumer expenditure function be denoted $\mathrm{e}\left(\mathrm{h}, \mathrm{q}^{\mathrm{F}}, \pi^{\mathrm{F}}, \mathrm{u}\right)$, and let the distorted GDP function be denoted $\widetilde{\mathrm{g}}\left(\mathrm{h}, \mathrm{q}^{\mathrm{M}}, \pi^{\mathrm{M}}, \gamma\right)$. The CES/CET functional versions of these functions have closed forms which are presented in a Technical Appendix available upon request. It is particularly useful that there are natural price and quantity aggregates (the former for unconstrained and the latter for constrained goods) for final and intermediate imports based on the assumed structure. ${ }^{9}$

The distorted functions inherit the derivative properties of the undistorted functions $\mathrm{e}\left(\mathrm{h}, \mathrm{p}^{\mathrm{F}}, \pi^{\mathrm{F}}, \mathrm{u}\right)$ and $\mathrm{g}\left(\mathrm{h}, \mathrm{p}^{\mathrm{M}}, \pi^{\mathrm{M}}, \gamma\right)$ save that input demands are subtracted in the GDP

\footnotetext{
${ }^{8}$ This assumption is quite extreme and overstates the impact of some nontariff barriers. The alternative is to ignore the NTB as a nonbinding quota. A conservative filter (discussed in the data section below) was used to specify goods subject to NTB, which tends to understate the impact of NTBs.

${ }^{9}$ The strong separability of the CES structure allows for closed form solutions for the price and quantity aggregates. In practice, the very large number of elements in $\widetilde{p}$ need not be calculated, but only an index of them. Details of the structure are available on request.
} 
function as opposed to final demands being added in the expenditure function. Thus $\mathrm{g}$ $\pi\left(\mathrm{h}, \mathrm{q}^{\mathrm{M}}, \pi^{\mathrm{M}}\right)$ is equal to the negative of the unconstrained input demand vector and $\mathrm{g}$ $\mathrm{q}(\mathrm{h}, \mathrm{q} M, \pi \mathrm{M})$ is equal to the vector of virtual prices of quota constrained inputs. ${ }^{10}$

The model is solved for the TRI in two steps. The first step is to obtain the virtual prices $\tilde{\mathrm{p}}$ associated with the new instruments and the old utility. These are found simultaneously with the nontraded good price $\tilde{h}$ associated with the new instruments and the old utility. $\tilde{h}$ is determined by the requirement that the nontraded good market clear:

$$
\widetilde{\mathrm{e}}_{\mathrm{h}}\left(\mathrm{h}, \mathrm{q}^{\mathrm{F}}, \pi^{\mathrm{F}}, \mathrm{u}\right)=\widetilde{\mathrm{g}}_{\mathrm{h}}\left(\mathrm{h}, \mathrm{q}^{\mathrm{M}}, \pi^{\mathrm{M}}, \gamma\right) .
$$

The implicit solution $\tilde{\mathrm{h}}(\mathrm{q}, \pi, \mathrm{u}, \gamma)$ is substituted into $\widetilde{e}_{\mathrm{q}}$ and $\widetilde{g}_{\mathrm{q}}$ at the point $\left(\mathrm{q}^{1}, \pi^{1}, \mathrm{u}^{0}, \gamma^{0}\right)$ to evaluate the virtual prices $\widetilde{p}^{\prime}=\left(\widetilde{p}^{F}, \widetilde{p}^{M}\right)$ equal to $\left(-\widetilde{e}_{q}\left(\widetilde{h}, q^{F 1}, \pi^{1}, u^{0}\right), \widetilde{g} q(\widetilde{h}\right.$ $\left.\left., \mathrm{q}^{\mathrm{M} 1}, \pi^{1}, \gamma^{0}\right)\right)^{\prime}$.

The second step is to calculate the equilibrium nontraded good price and the TRI. The new levels of the instruments imply domestic prices equal to $\widetilde{p}, \pi^{1}$. Deflating the domestic prices of tariff and tariff-equivalent ridden goods by $\Delta$, the nontraded good market clearance equation is:

$$
\mathrm{e}_{\mathrm{h}}\left(\mathrm{h}, \tilde{\mathrm{p}} / \Delta, \pi^{1} / \Delta, \mathrm{u}^{0}\right)=\mathrm{g}_{\mathrm{h}}\left(\mathrm{h}, \tilde{\mathrm{p}} / \Delta, \pi^{1} / \Delta, \gamma^{0}\right) .
$$

Here, it should be understood that $\tilde{p} / \Delta$ affects $g$ and $g_{h}$ only through its elements which are prices of imported inputs while it affects e and $\mathrm{e}_{\mathrm{h}}$ only through its elements which are final imports. This equation is solved for $\mathrm{h}$ and $\Delta$ simultaneously with the balance of payments constraint:

$$
\mathrm{e}\left(\mathrm{h}, \tilde{\mathrm{p}} / \Delta, \pi^{1} / \Delta, \mathrm{u}^{0}\right)-\mathrm{g}\left(\mathrm{h}, \tilde{\mathrm{p}} / \Delta, \pi^{1} / \Delta, \gamma^{0}\right)-\left(\pi^{1 / \Delta}-\pi^{*}\right)^{\prime}\left[\mathrm{e}_{\pi}-\mathrm{g}_{\pi}\right]-\mathrm{tq}^{\prime} \mathrm{q}^{1} .
$$

\section{Alternative Treatments of NTB-constrained goods}

\footnotetext{
${ }^{10}$ The distorted trade expenditure function $\widetilde{\mathrm{E}}(\mathrm{q}, \pi, \mathrm{u}, \gamma)$ which subsumes the nontraded good price $\mathrm{h}$ is equal to $\max \left\{\widetilde{\mathrm{e}}\left(\mathrm{h}, \mathrm{q}^{\mathrm{F}}, \pi^{\mathrm{F}}, \mathrm{u}\right)-\widetilde{\mathrm{g}}\left(\mathrm{h}, \mathrm{q}^{\mathrm{M}}, \pi^{\mathrm{M}}, \gamma\right)\right\}$. 
Two more problems arise in practice with the evaluation of quotas. The first problem is with the meaning of the 'new' trade policy in the presence of economic growth when making year-on-year comparisons. $\mathrm{q}^{1}$ could be taken to be the actual quota in the new year. Alternatively, however, recognizing that growth will make an unchanging quota more restrictive, the new policy $\mathrm{q}^{1}$ is defined to be the actual quota in the new year deflated by the aggregate GDP growth factor. Intuitively, for neutral growth (radial expansion of production and consumption) a quota is equi-restrictive as it grows at the growth rate. See Anderson and Neary (1994) for a full discussion.

The second practical problem with evaluation of changes in quota policy is what to do with changing levels of the rent-retaining tariff. th is a lump sum (nondistortionary) instrument, so it is kept constant at the initial level for year-on-year evaluations designed to evaluate trade restrictiveness. However, if the 'new' policy is free trade, two alternative TRI evaluations are possible. First, as with the year-on-year evaluation, keep the rent-retaining tariff at its initial level and tighten quotas so that virtual prices rise in step with tariff-ridden prices; all so as to reduce real income to its initial distorted level $u^{0}$. But second, switch to tariffs for formerly quota-constrained imports and find the uniform tariff on all distorted imports which reduces real income to its initial distorted level $\mathrm{u}^{0}$. The latter procedure in principle is always more efficient than the former since in effect the 'rent-retaining' tariff always captures all the rent. Thus the 'efficient' uniform tariff equivalent will always be larger (a higher 'efficient'uniform tariff equivalent is required to reduce welfare to $\mathrm{u}^{\uparrow}$ than with the quota policy which gives away some rent).

For the comparison of the base policy with free trade, it is necessary to have estimates of free trade quantities or prices. In the absence of such data, there are three different treatments of NTB-constrained goods presented below. The first expedient, the nonbinding NTB case, assumes that rent-retaining tariffs capture all the quota rent so the NTB is nonbinding at the margin in the initial equilibrium. Then the actual policy is fully equivalent to a tariffs only policy, and the TRI is calculated by uniformly raising all 
distorted prices from the free trade level. This means that rent-retaining tariffs are now varied in the 'uniform tariff equivalent'. In other words, an implicit quota policy is combined with an efficient rent-retaining tariff policy.

The second expedient for treating NTB-constrained goods is to assume that free trade implies a uniform 10\% increase in NTB constrained imports. The TRI is calculated by (implicitly) restricting quantities so that the domestic prices of NTB-constrained goods rise uniformly, in step with the rise in tariff-ridden goods. Rent is lost save for that retained by the fixed rent-retaining tariffs.

The third expedient builds on the first 'as if tariffs' treatment, but with the difference that the initial rent-retaining tariffs are assumed to leave out a uniform retained rent premium worth $10 \%$ of the base external price. The TRI in this case also includes variation in the rent-retaining tariff, so that in effect the policy switches from a rent-losing quotacum-tariff policy to an full rent retention quota-cum-tariff policy. In contrast to the second expedient, there is a switch to an efficient rent-retaining tariff on formerly NTB-constrained goods. The results show the predicted larger uniform tariff equivalent, though in many instances the difference is quite small.

\section{Data and Operational Considerations}

\section{A. Data}

The primary data for the calculations consists of trade flows, tariffs and nontariff barrier classification for a detailed set of imports, consisting of about 12004 digit HS code categories for each of 28 countries, and for two adjacent years for the year-on-year sample. The 28 country cross section and the panel of 7 year-on-year cases are described in the Appendix. The data were assembled by the World Bank staff at IECIT (mostly taken from the TRAINS data set maintained by UNCTAD). Below the 4 digit HS codes are separately classified data sets for trade, tariffs and 'hard core' NTBs which are concorded and aggregated using trade weights. A given line of trade is deemed to be restricted by 
NTBs if $75 \%$ or more of the underlying categories are subject to NTBs. This conservative procedure eliminated a number of NTBs from further treatment. In addition to the primary data for the calculations it is necessary to enter commonly available data such as GDP, total exports and the current account surplus, all of which are available from the World

\section{Development Report.}

The imports data are split into final and intermediate imports on the basis of the definition of the various product lines. The split produces roughly 600 lines of each type of import.

Elasticities of substitution are assumed with little empirical foundation. In order to restrict the response of the nontraded good price in the model, the elasticity of transformation in the base case is quite high, equal to 5. Empirically, input substitution elasticities tend to be smaller than final substitution elasticities, so the base case sets them at .7 and 2 respectively. Sensitivity analysis shows that changes in the elasticity values do not much affect the results.

\section{B. The TRI calculation}

The model is solved on an Excel 4.0 spreadsheet, available from the author on request. It converges quickly on any modern personal computer and is usually 'well behaved'.11 The data are entered into the supporting worksheets. Documentation available from the author describes the process.

\section{Restrictiveness Relative to Free Trade}

The results of the 28 country benchmark study are presented below. In subsection A, the TRI is compared to the standard index numbers such as trade weighted average tariffs. The TRI calculations reported in subsection A are based on the nonbinding NTB

\footnotetext{
${ }^{11}$ It is well-known that solutions to nonlinear systems of equations can be sensitive to starting values. Also, multiple solutions can exist, since balance of trade functions of distorted economies are not necessarily convex. This is true even for the CES/CET case. The model sometimes did not converge when very large and heterogeneous annual changes were found, suggesting the inappropriateness of the CES/CET model specification.
} 
case: all quota rent is assumed to be captured by rent-retaining tariffs. Subsection B reports on the other two treatments of NTBs. No one of the three treatments is more credible than the others, but the priority of place given to the nonbinding NTB case may be justified by the clean behavioral story which can be told: with rent retaining tariffs available, a constrained-revenue-maximizing government does not leave rent lying in the street. Subsection C reports on the sensitivity of TRI estimates to the elasticities of substitution and to the share of rent (above that retained by rent-retaining tariffs) assumed to be lost.

Table A.1 in the Appendix presents the countries and years covered. They include a range of levels of development and of levels and types of trade intervention. A third of the countries are developed, including the US, Switzerland and Australia. Some have long been liberal traders, while others have recently liberalized and still others remain heavily protectionist. About a third of the countries under the criteria used ('hard core' NTBs in at least $75 \%$ of underlying categories within at least one detailed import line) have no effective NTBs.

\section{A. The TRI and Standard Measures: nonbinding NTBs}

Table A.2 in the Appendix presents the details of various calculated measures of trade restriction for the entire group of countries covered in the study. This section presents various summary statistics based on that data table.

The TRI is calculated as a tariff factor deflator, good for making the connection with index number theory. With a comparison to free trade, however, it is more intuitive to work with a uniform tariff equivalent (equal to the inverse of the TRI minus one). The results of Table A.2 show that the uniform tariff equivalent (the inverse of the TRI minus one) is systematically greater than the overall average tariff; in only 1 of 28 cases shown does the average tariff overstate the true degree of trade restrictiveness. The sample mean of the trade weighted average tariff is equal to $11.96 \%$, as compared to the sample mean of the uniform tariff equivalent equal to $18.91 \%$. Thus the magnitude of the added trade restrictiveness omitted by the average tariff is generally large. The 'relative error', the 
percentage deviation of the uniform tariff equivalent from the trade weighted average tariff, averaged across the sample is equal to $55 \%$ (specifically, the sample mean of the difference between the uniform tariff equivalent and the average tariff, all relative to the average tariff, is equal to 0.55$)$. The variability of the relative error within the sample is large, with a coefficient of variation equal to .921 .

The relative error is weakly related to some summary characteristics of nations and their trade policies. First, the relative error is uncorrelated with the average tariff (a correlation coefficient equal to 0.079 ). Second, the relative error is fairly highly positively correlated with dispersion in the tariff structure as measured by the trade weighted coefficient of variation (correlation coefficients of 0.738 for final imports and 0.709 for intermediate imports). This finding tends to give a bit of legitimacy to the efforts of earlier analysts to account for the potential extra restrictiveness of tariff dispersion with use of the coefficient of variation. Third, the relative error is uncorrelated with the use of NTBs (a correlation coefficient equal to 0.044 ). Fourth, the relative error tends weakly to fall with the stage of economic development (a correlation coefficient equal to -0.143).

An important practical issue is to rank countries by their trade restrictiveness. The rank correlation of the uniform tariff equivalent and the trade weighted average tariff is 0.642, significantly different from zero, and significantly different from one. ${ }^{12}$ However, the ordinary correlation of the uniform tariff equivalent and the trade weighted average tariff is high, with a coefficient equal to 0.935 . The correlation results taken alone could be interpreted as weakly supporting the use of average tariffs as an index of trade restrictiveness in regression analysis of, for example, openness and growth. However, there are several good reasons to reject this inference. First, the rank and simple correlation of the TRI and the average tariff is much reduced with alternative treatments of NTBs. Second, tracking trade liberalization through time for a set of countries, which is required

\footnotetext{
${ }^{12}$ To test the null hypothesis of perfect rank correlation between $\mathrm{x}$ and $\mathrm{y}, \mathrm{I}$ calculated the rank correlation between $\mathrm{x}$ and a difference variable equal to $\operatorname{rank}(\mathrm{x})-\operatorname{rank}(\mathrm{y})$.
} 
February 19, 1996

for openness and growth studies, involves moving each country in each year from one distorted position to another, not moving from an initial distorted position to free trade. Subsection III.C reports results with year-on-year changes in trade policy for a small set of countries showing that changes in the TRI and the standard indices were very weakly (sometimes negatively) correlated in the cross-section-time-series. The higher cross section correlation found here in contrast arises from the very simple form and the large jump involved in moving (unrealistically) to free trade --- the change in every type of indicator indicates a fall in restrictiveness. In data for year-on-year changes, the mean and dispersion of tariffs move in conflicting directions, NTB coverage changes, and the level of various quotas shifts non-uniformly. This aspect of the analysis of trade restrictivenss shows up in the large and quite variable 'relative error' in the cross-section sample of countries, as the TRI implied by different national distortion structures is compared to the average tariff.

\section{B. The TRI with Alternative Treatment of NTBs}

The method of dealing with NTBs used to calculate the TRI in subsection A is to assume that all quota rent is captured with rent-retaining tariffs in the equivalent equilibrium. The model is fully equivalent to one with tariffs only. Two alternatives are explored in this section.

The first alternative is to assume that all NTB-constrained categories have domestic prices inflated by a unit quota rent equal to $10 \%$ of the external price, in addition to the rent retaining tariff. All quota rent (beyond that captured by the rent-retaining tariff) in the initial equilibrium is assumed to be lost to foreigners or to rent-seeking. A reversion to free trade secures a terms of trade improvement of $10 \%$ for NTB-constrained categories. The TRI for this case is calculated by assuming that a uniform tariff is levied, including one on NTB-constrained categories. This has the effect of potentially capturing rent which was previously lost (depending on the level of the rent-retaining tariff in the initial equilibrium). This case will subsequently be referred to as the $10 \%$ premium case. 
The $10 \%$ premium case TRI measures have somewhat higher sample mean uniform tariff equivalent than those of the nonbinding NTB case $(25.4 \%$ as compared to 18.9\%). This indicates the initial policy is even more restrictive than in the preceding case, due to the rent loss on NTB constrained goods. The two sets of TRIs are fairly highly correlated (a simple correlation coefficient equal to 0.88 and a rank correlation coefficient equal to 0.71 ). The sample mean relative error from using the trade weighted average tariff instead of the TRI rises from $55 \%$ to $108 \%$ of the average tariff. The correlations of the relative error with the NTB and stage of development variables increase substantially, while the correlation of the relative error with the coefficient of variation of final tariffs falls substantially. Most significantly, the rank correlation of the TRI and the average tariff falls to .299 .

The second procedure for dealing with NTBs is to assume that 'free trade' causes a uniform $10 \%$ rise in quantities in the NTB-constrained categories. From this position the TRI finds the uniform deflator which is just as inefficient as the initial policy, where the domestic price vectors of NTB constrained goods must be uniformly raised by implicitly tightening the quotas to do the job. Rent-retaining tariffs are maintained at the initial level in this operation, and are assumed to capture all rent (no other premium is lost). This case is presented to demonstrate the sensitivity of results to treatment of quotas rather than for any attempt at realism. The $10 \%$ quantity increase case has a uniform tariff equivalent which is always lower than in the nonbinding NTB case, usually quite close but sometimes substantially different. Table 1 shows a case in which the differences are large (India), in contrast to a case in which the differences are smaller (the US). The table also shows the effect of different treatment of rent-retaining tariffs. A fall in rent-retaining tariffs is inefficient, other things being equal, so it matters whether the 'free trade' policy is based on zero rent retaining tariffs or on the initial rent retaining tariffs. As a further indication of the sensitivity of results to the treatment of NTBs, the uniform tariff equivalent in the $10 \%$ 
quantity increase case is uncorrelated with that in the nonbinding NTB case (a coefficient of $0.064)$.

Table 1. TRIs for Alternative NTB Treatments ${ }^{13}$

$\begin{array}{llll} & \text { Nonbinding NTB } & 10 \% \text { quantity rise, } & 10 \% \text { quantity rise, } \mathrm{tq} \\ & \text { case } & \text { initial } \mathrm{tq} & \text { equal to zero } \\ \text { India } & 0.760 & 0.860 & 0.964 \\ \text { US } & 0.943 & 0.931 & 0.966\end{array}$

A related aspect of the treatment of NTBs is to allow the share of rent retained to be an intermediate value rather than either 0 or 1 . The TRI results are rather sensitive to the rent share assumption. In a typical case, that of Mexico in 1989 under the $10 \%$ quantity expansion assumption, a drop from complete rent loss to a 50\% rent loss results in a more than $4 \%$ fall in the TRI (from 0.894 to 0.851 ). The initial equilibrium works out to be more distorted (liberalization results in a smaller TRI) with a rent share assumption of $50 \%$, an empirical result which can be explained theoretically by noting that the shadow price of quotas is a decreasing function of the rent share parameter, cet. par., when evaluated at the point where the rent loss is equal to 100\% (see Anderson and Neary, 1992 for the formula for the shadow price of quotas in a model which encompasses the model used here).

\section{Sensitivity to Elasticities}

Table 2 below presents a sensitivity analysis of TRIs calculated for Mexico in 1989 with respect to variation in elasticities of substitution in intermediate and final demand for

\footnotetext{
${ }^{13}$ For an assumed uniform tariff which is as restrictive as the initial policy India requires a tariff equal to .316 (equal to $1 / .76-1$ ). For a $10 \%$ quantity rise with the initial rent-retaining tariffs, the 'tariff equivalent' is equal to .163 (equal to $1 / .86-1$ ). This is the policy of a tariff of .163 plus a quota policy which raises domestic prices of quota constrained goods by $16.3 \%$ relative to free trade, all while maintaining the initial rent retaining tariffs. Finally, the policy of zero rent retaining tariffs results in a TRI equal to .964 . The higher value ('free trade' is less advantageous) is due the absence of rentretaining tariffs when a quota is present. For the US case the differences are much smaller. Moreover, the $10 \%$ quantity increase while maintaining the initial rent retaining tariffs results in a TRI which is smaller than the 'tariff equivalent' TRI, showing that there is no necessary relation between these two measures.
} 
imports. Also, the quota expansion version of the liberalization experiment is tested for sensitivity with respect to the rent loss share. ${ }^{14}$ The base case is in bold type. The results show that elasticity variation is not very influential save for the lowest value of input substitution in the case of a $10 \%$ uniform quota expansion.

${ }^{14}$ This parameter can have no effect on the 'nonbinding quota' version of the treatment of trade distortions. 
Table 2. Sensitivity Analysis of Mexican TRI, 1989

\begin{tabular}{|c|c|c|c|}
\hline & Parameters & $\begin{array}{l}\text { Nonbinding NTB } \\
\text { case }\end{array}$ & $\begin{array}{l}\text { Uniform } 10 \% \text { Quota } \\
\text { Expansion case }\end{array}$ \\
\hline \multirow{4}{*}{$\begin{array}{l}\text { Final Substitution } \\
\text { Elasticity }\end{array}$} & 1.05 & .8984 & .8912 \\
\hline & & & \\
\hline & 2 & .8896 & .8940 \\
\hline & 3 & .8882 & .8913 \\
\hline \multirow{3}{*}{$\begin{array}{l}\text { Input Substitution } \\
\text { Elasticity }\end{array}$} & .2 & .8855 & .8613 \\
\hline & .7 & .8896 & .8940 \\
\hline & 1.2 & .8918 & .8997 \\
\hline
\end{tabular}

These sensitivity results are representative of the sample of countries studied.

\section{Changes in Trade Restrictiveness}

The TRI is a solution to the problem of evaluating the annual movement of trade restrictiveness, as arises in the investigation of the link between openness and growth and in evaluation of trade liberalization as a condition for further loans under the World Bank's Structural Adjustment Loan program. The results show that standard measures, conceptually flawed as they are, are also practically very misleading.

Seven cases of year-on-year changes in protection for typical developing countries are analyzed in Table 3 with both the standard measures and TRI. Looking at the standard measures such as the mean and dispersion of tariffs, it is striking how often they appear to conflict in their apparent implications. For Colombia from 1989 to 1990, the average tariffs fall, but this is mainly due to a fall in tariffs on NTB-constrained goods, which is inefficient. However, the trade-weighted coefficient of variation of tariffs falls, which is supposed to be efficient. finally, the NTB coverage ratio falls and the quota levels rise, both of which are supposed to be efficient. The TRI resolves these conflicting indicators into a single meaningful index number which shows that Colombia did indeed liberalize, 
effectively lowering tariffs by $4 \%$. (Strictly, a uniform tariff surcharge and surcharge equivalent of $4 \%$ is required to offset the liberalization of 1989-90.) 
February 19, 1996

Trade Restrictiveness Benchmarks

\section{Table 3. Changes in Trade Distortion Measures}

(numbers are decimal percentage changes, except as indicated)

Mor 84-5 Mor 86-8 Col 89-90 Pak 86-8 Tun 87-8 Tun 88-9 Arg 85-88

Average Tariffs

$\begin{array}{lccccccc}\text { FINAL } & 0.009 & 0.026 & -0.064 & 0.019 & -0.027 & -0.007 & 0.099 \\ \text { unconstrained } & -0.008 & -0.047 & 0.007 & 0.041 & -0.013 & 0.055 & 0.129 \\ \text { constrained } & 0.011 & 0.056 & -0.029 & 0.042 & -0.024 & -0.011 & 0.069 \\ \text { INTERMEDIATE } & -0.003 & 0.151 & -0.034 & -0.021 & 0.000 & 0.003 & 0.015 \\ \text { unconstrained } & -0.003 & 0.151 & -0.001 & -0.157 & 0.039 & -0.023 & 0.057 \\ \text { constrained } & -0.001 & 0.151 & -0.025 & -0.109 & -0.014 & 0.049 & -0.053 \\ \text { Coefficient of Variation } & \text { of Tariffs } & & & & & & \\ \text { final } & -0.327 & -0.086 & 0.044 & -0.124 & 0.030 & 0.039 & 0.200 \\ \text { intermediate } & -0.138 & -0.742 & 0.029 & 0.011 & -0.137 & 0.006 & 0.035 \\ \text { NTB coverage } & & & & & & & \\ \text { final } & 0.000 & -0.091 & -0.335 & -0.320 & -0.065 & -0.101 & -0.567 \\ \text { intermediate } & 0.000 & -0.005 & -0.416 & -0.717 & -0.070 & -0.141 & -0.411 \\ \text { NTB quota change } & & & & & & & \\ \text { final } & -0.138 & 0.019 & 0.120 & 0.166 & 0.243 & 0.215 & 0.661 \\ \text { intermediate } & -0.022 & 0.159 & 0.120 & 0.217 & 0.232 & 0.132 & 0.355 \\ \text { TRI } & & & & & & & \\ \text { change in tri } & 0.109 & 0.031 & -0.041 & 0.226 & -0.121 & -0.117 & -0.263 \\ \text { tri level } & 1.109 & 1.031 & 0.959 & 1.226 & 0.879 & 0.883 & 0.737 \\ \text { Welfare } & & & & & & & \\ \text { welfare change } & -0.002 & -0.001 & 0.003 & -0.039 & 0.030 & 0.030 & 0.019 \\ \text { welfare change } & 0.998 & 0.999 & 1.003 & 0.961 & 1.030 & 1.030 & 1.019\end{array}$

factor

Looking across the rows for the TRI and the standard measures, the behavior of the changes in the various measures appear to be weakly correlated or even have the wrong sign. This is confirmed with correlation analysis in Table 4. Dramatically, the TRI has the 'wrong sign' in most correlations: the changes in average tariffs and in dispersion of tariffs is negatively correlated with the TRI. The changes in the final and intermediate NTB 
coverage ratios have respectively positive and negative correlation with the change in the TRI. The only indicator with the 'right' sign is the NTB quantity change. The correlation of the changes in the TRI and welfare (measured by money metric utility based on the initial prices) is reported in the last row of Table 4. Economic theory predicts that the sign of changes in money metric utility and in the TRI must be opposite, but does not restrict the correlation to be minus one. In the event, the correlation is fairly strong at -0.86 .

\section{Table 4. Correlation of the TRI and Standard Measures}

$\begin{array}{ll}\text { Average tariffs } & \\ \text { final } & -0.238 \\ \text { intermediate } & -0.010 \\ \text { coefficients of variation } & \\ \text { final } & -0.827 \\ \text { intermediate } & -0.198 \\ \text { NTB coverage ratio } & \\ \text { final } & 0.355 \\ \text { intermediate } & -0.213 \\ \text { NTB quantity change } & \\ \text { final } & -0.737 \\ \text { intermediate } & -0.531 \\ & \\ \text { Welfare } & -0.861\end{array}$

These results taken together show that the TRI differs very significantly from standard measures in practice. Thus the conceptual problem the TRI resolves is also practically very important.

\section{Trade Restrictiveness, Trade and Growth}

The availability of a superior instrument to measure trade restrictiveness stimulates a reexamination of several well-known empirical relationships between policy restrictiveness, trade and growth. The results show that the TRI gives a significantly different picture of such relationships. 
As a preliminary step it is interesting to correlate trade restrictiveness as measured by the uniform tariff equivalent with several country characteristics to 'explain' protection. First, the uniform tariff equivalent is essentially uncorrelated with the use of NTBs (a coefficient of 0.114 for the zero premium case, a coefficient of 0.243 for the $10 \%$ premium case and a coefficient of -0.088 for the $10 \%$ quantity increase case). Second, the uniform tariff equivalent is negatively correlated with the stage of economic development for the nonbinding NTB case (a coefficient of -0.395) and for the $10 \%$ premium case ($0.285)$ but weakly positively correlated for the $10 \%$ quantity increase case ( 0.121$)$.

Does openness to trade tend to fall with the level of protection? In the 28 country sample, the uniform tariff equivalent is weakly negatively correlated with the import share in all cases; with coefficients equal to -0.149 in the nonbinding NTB case, -0.280 for the $10 \%$ quantity increase case and -0.147 in the $10 \%$ premium case. It is also worth noting that the average tariff and the import share are negatively correlated (with a coefficient equal to -0.349). A negative sign may be rationalized by the substitution effect, but the correlation clearly reflects other factors as well, such as political economy. ${ }^{15}$

Does openness help raise economic growth? The correlation of imports/GDP and growth in the sample is 0.376, confirming a link noted in the literature (Edwards, 1993). Since protection as measured by the TRI tends to depress trade in the sample, the two links together tend to indicate that protection depresses growth. However, the uniform tariff equivalent is positively correlated with the growth rate of GDP for all three cases in the sample. The coefficients are equal to .286 for the nonbinding NTB case, 0.152 for the $10 \%$ quantity increase case and 0.229 for the $10 \%$ premium case. This positive correlation of the TRI and the GDP growth rate casts doubt on the 'policy openness and growth'

\footnotetext{
${ }^{15}$ On theoretical grounds, the substitution effect implies a negative relation between the average tariff and the imports share, provided elasticities of substitution exceed one and tariff structures maintain relative prices in the cross section. There is no prediction about such a relationship for the uniform tariff equivalent.
} 
hypothesis. In partial contrast, the correlation between the average tariff and the growth rate is equal to 0.064 , not significantly different from zero.

The correlations reported here are meant only to indicate the potential usefulness and practical importance of the TRI in 'openness and growth' investigations. An important difficulty with these studies is the absence of a measure of trade policy, which the TRI can ameliorate. A full investigation of the linkage between policy and growth variables requires first building a theoretical structure, including an intertemporal structure in which the TRI accurately measures policy restrictiveness at a point in time for the purpose of the analysis, and then implementing it on 'panel' data.

\section{Vl. Conclusion}

This paper reports on measures of the distance of trade policy from free trade for a 28 country sample using the TRI. The TRI measures differ significantly from standard measures of trade restrictiveness. Average tariffs generally underestimate the 'uniform tariff equivalent', with the degree of underestimate positively correlated with the dispersion of the tariff structure. The rank correlation of the TRI and the average tariff is significantly different from zero but also significantly different from one. These conclusions appear to be robust with respect to missing data problems. The magnitude of the TRI is not very sensitive to elasticity of substitution variation, but is sensitive to the assumptions used to treat NTBs.

The paper also reports on measures of year-on-year changes in trade restrictiveness for 7 cases using the TRI and the standard measures. Here the TRI and the standard measures differ very dramatically, with negative correlation between the TRI and most standard measures. This is because in yearly changes the mean and dispersion of tariffs as well as indicators of quota policy often move in conflicting directions, so any one of the (flawed) measures has less chance of even giving the right sign, let alone magnitude. 
The concluding section explores some links between trade restrictiveness, trade and growth. For what it is worth based on the sample here, high protection measured by the average tariff is uncorrelated with growth while high protection measured by the TRI is positively correlated with growth. These results show that the TRI behaves significantly differently from other measures of trade restrictiveness in the context of openness and growth and may be useful in advancing understanding of the link between openness and growth. 


\section{Data Appendix}

Table 1. Countries Included in the Study Country Code Full Name Year

AG

AT

$A U$

BO

BR

CA

$\mathrm{CH}$

EC

$\mathrm{FI}$

$\mathrm{HK}$

$\mathrm{HU}$

ID

IN

MR

$\mathrm{MX}$

MY

NO

NZ

PE

$\mathrm{PH}$

PK

$P L$

PY

$\mathrm{TH}$

TN

US

VE
Argentina 1985

Austria 1988

Australia 1988

Bolivia 1991

Brazil 1989

Canada 1990

Switzerland 1988

Ecuador 1991

Finland 1988

Hong Kong 1991

Hungary 1991

Indonesia 1989

India 1991

Morocco 1984

Mexico 1989

Malaysia 1988

Norway 1988

New Zealand 1988

Peru 1991

Philippines 1991

Pakistan 1986

Poland 1989

Paraguay 1990

Thailand 1988

Tunisia 1991

USA 1990

Venezuela 1991 
February 19, 1996

Trade Restrictiveness Benchmarks

Table A.2 The TRI (nonbinding NTB case) and other Tariff Measures

\begin{tabular}{|c|c|c|c|c|c|c|c|c|c|}
\hline country & $\begin{array}{l}\text { Uniform } \\
\text { tariff eq. }\end{array}$ & $\begin{array}{c}\text { overall ave. } \\
\text { tariff }\end{array}$ & $\begin{array}{c}\text { ave tariff } \\
\text { final }\end{array}$ & $\begin{array}{c}\text { ave tariff } \\
\text { int. }\end{array}$ & $\begin{array}{l}\text { cfvar } \\
\text { final }\end{array}$ & $\begin{array}{l}\text { cfvr } \\
\text { int. }\end{array}$ & NTB & $\begin{array}{l}\text { Devel- } \\
\text { oped } \\
\end{array}$ & $\begin{array}{c}\text { error/ } \\
\text { ave tar }\end{array}$ \\
\hline AT & 0.1999 & 0.1062 & 0.1444 & 0.0679 & 0.7904 & 0.8652 & 0 & 1 & 0.8817 \\
\hline $\mathrm{BO}$ & 0.0931 & 0.0944 & 0.0916 & 0.0980 & 0.1672 & 0.0876 & 0 & 0 & -0.0144 \\
\hline CO & 0.1245 & 0.1002 & 0.1202 & 0.0871 & 0.4719 & 0.5129 & 0 & 0 & 0.2424 \\
\hline EC & 0.0947 & 0.0655 & 0.0726 & 0.0591 & 0.7445 & 0.7525 & 0 & 0 & 0.4458 \\
\hline MY & 0.2104 & 0.0970 & 0.1049 & 0.0928 & 1.1218 & 1.0896 & 0 & 0 & 1.1688 \\
\hline PE & 0.1595 & 0.1575 & 0.1583 & 0.1567 & 0.1601 & 0.1351 & 0 & 0 & 0.0127 \\
\hline PY & 0.1784 & 0.1254 & 0.1341 & 0.1126 & 0.7494 & 0.8618 & 0 & 0 & 0.4233 \\
\hline $\mathrm{TN}$ & 0.1855 & 0.0986 & 0.0985 & 0.0988 & 1.2782 & 1.3107 & 0 & 0 & 0.8811 \\
\hline VE & 0.2107 & 0.1291 & 0.1596 & 0.1074 & 0.8376 & 0.6628 & 0 & 0 & 0.6322 \\
\hline$A G$ & 0.1955 & 0.1806 & 0.3600 & 0.8600 & 0.6060 & 0.6150 & 1 & 0 & 0.0825 \\
\hline $\mathrm{AU}$ & 0.1662 & 0.1078 & 0.1199 & 0.0934 & 0.9743 & 0.9993 & 1 & 1 & 0.5418 \\
\hline BR & 0.2327 & 0.1613 & 0.1919 & 0.1474 & 0.7766 & 0.8171 & 1 & 0 & 0.4431 \\
\hline $\mathrm{CA}$ & 0.0955 & 0.0695 & 0.0808 & 0.0611 & 0.6329 & 0.8573 & 1 & 1 & 0.3741 \\
\hline $\mathrm{CH}$ & 0.0000 & 0.0000 & 0.0000 & 0.0000 & 0.0000 & 0.0000 & 1 & 1 & 0 \\
\hline $\mathrm{FI}$ & 0.1257 & 0.0604 & 0.0653 & 0.0405 & 1.1635 & 1.5174 & 1 & 1 & 1.0801 \\
\hline $\mathrm{HK}$ & 0.0000 & 0.0000 & 0.0000 & 0.0000 & 0.0000 & 0.0000 & 1 & 1 & 0 \\
\hline $\mathrm{HU}$ & 0.1526 & 0.0914 & 0.1250 & 0.0620 & 0.8614 & 0.9814 & 1 & 0 & 0.6693 \\
\hline ID & 0.3036 & 0.1276 & 0.1792 & 0.0912 & 1.3535 & 1.0140 & 1 & 0 & 1.3781 \\
\hline IN & 0.3155 & 0.1531 & 0.2117 & 0.1651 & 0.9016 & 1.7079 & 1 & 0 & 1.0611 \\
\hline MR & 0.1846 & 0.0705 & 0.1910 & 0.0470 & 1.2250 & 2.2200 & 1 & 0 & 1.6186 \\
\hline$M X$ & 0.1241 & 0.1080 & 0.1165 & 0.1014 & 0.4248 & 0.5017 & 1 & 0 & 0.1491 \\
\hline NO & 0.0844 & 0.0453 & 0.0447 & 0.0426 & 1.3553 & 1.2966 & 1 & 1 & 0.8631 \\
\hline NZ & 0.1364 & 0.0792 & 0.1047 & 0.0559 & 0.7546 & 1.2521 & 1 & 1 & 0.7228 \\
\hline PK & 0.8762 & 0.4523 & 0.3840 & 0.6490 & 0.7940 & 0.9300 & 1 & 0 & 0.9371 \\
\hline $\mathrm{PH}$ & 0.1734 & 0.1416 & 0.1619 & 0.1318 & 0.4633 & 0.5124 & 1 & 0 & 0.2242 \\
\hline PL & 0.1450 & 0.0869 & 0.1083 & 0.0677 & 0.9654 & 1.0180 & 1 & 0 & 0.6694 \\
\hline $\mathrm{TH}$ & 0.4467 & 0.3196 & 0.3812 & 0.2964 & 0.7406 & 0.5705 & 1 & 0 & 0.3975 \\
\hline US & 0.0610 & 0.0393 & 0.0456 & 0.0277 & 0.9158 & 1.1331 & 1 & 1 & 0.5502 \\
\hline
\end{tabular}


for the referees, not for publication

\section{Technical Appendix to Trade Restrictiveness Benchmarks}

This appendix lays out the mathematical formalization of the CES/CET model used to calculate the TRI in "Trade Restrictiveness Benchmarks". To build intuition prior to the formalism, a preliminary graphical analysis of the CES/CET model is presented in the introduction. Then section A.1 develops the CES expenditure and distorted expenditure functions. Next, the CES/CET cost and product functions are presented in section A.2. Finally, section A.3 discusses general equilibrium in the model.

The intuition of the CES/CET model is seen in three diagrams. The first diagram shows the final output and final demand structure of the model, dubbed the Australian model for its resemblance to the Salter-Swan model. The export good is the numeraire, the external price of the final import is conventionally set equal to one, and balanced trade requires that $\mathrm{OF}$, the volume of final imports (these being the only imports) equal OG, the volume of imports. The joint output of the nontraded good and of exports is selected along transformation surface TT to maximize national income at any given price of the nontraded good, represented by the inverse of the absolute value of the slope of budget line DE. With national income in terms of the nontraded good equal to OD, the representative consumer selects a utility-maximizing bundle along budget line DC, with slope equal to the inverse of the nontraded good's price.

The effect of a tariff in this model is shown in the second diagram. The domestic relative price of the import is wedged above the international price, resulting in the marginal rate of substitution at $\mathrm{C}^{\prime}$ being greater than the absolute slope of the international budget line $\mathrm{D}^{\prime} \mathrm{C}^{\prime}$. The international relative price, equal to the absolute slope of $\mathrm{D}^{\prime} \mathrm{C}^{\prime}$ is lower than the relative price at free trade, equal to the absolute slope of DC. This is because the price of the nontraded good is driven up as consumers are driven from tariff ridden imports to 
domestic substitutes. In the analysis, all tariff revenue is rebated and trade remains balanced in both situations.
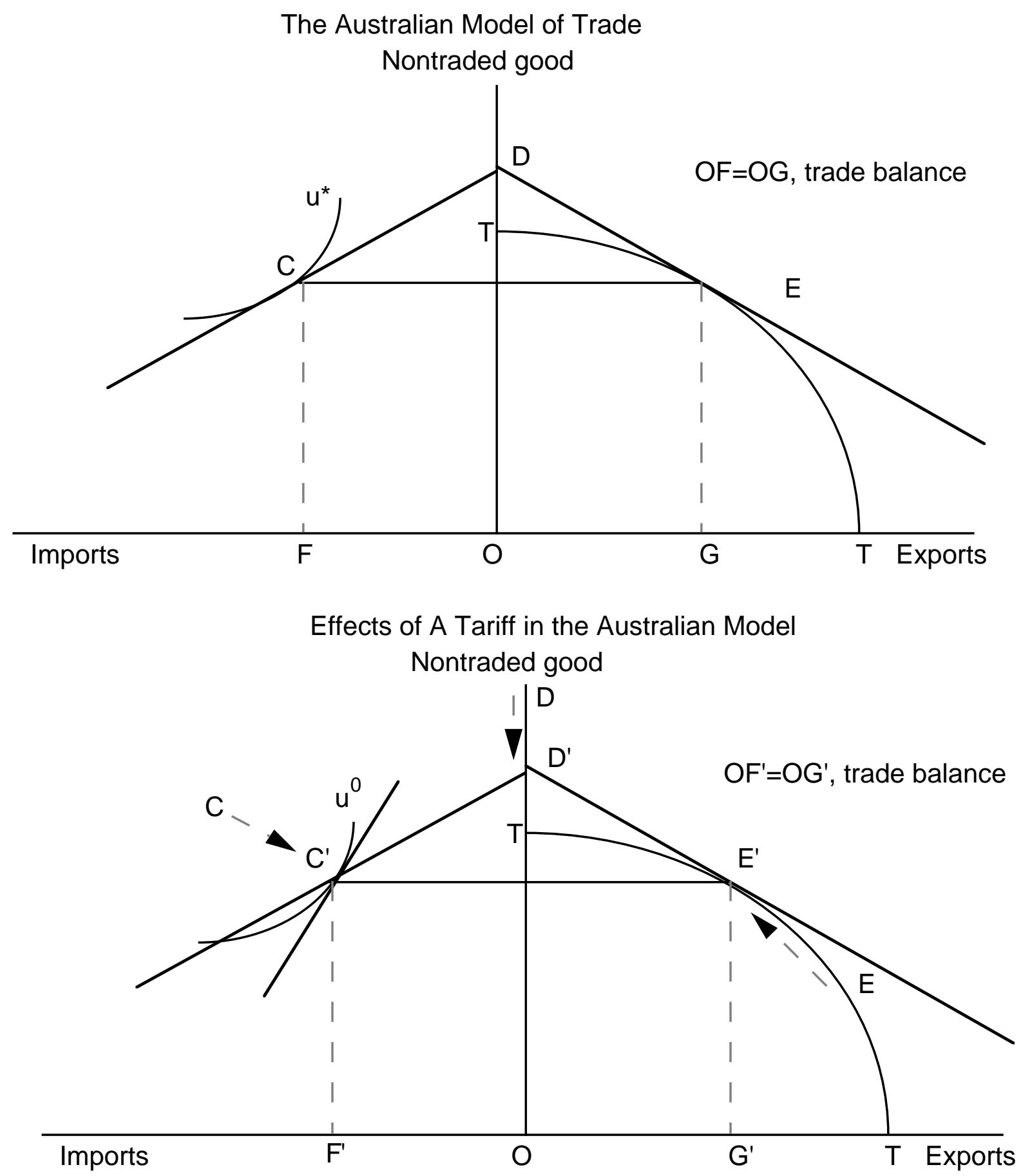

The introduction of imported inputs is heuristically shown in the third diagram.

Here, the curved production function has diminishing returns to the variable imported input 
February 19, 1996

due to the fixed primary factor labor. With no tariff, the value of marginal product condition implies a solution at A, with domestic activity OD, implying a given distance from the origin for TT. OC is equal to gross domestic product. Conventionally, the price of the nontraded good is equal to one. With a tariff, the solution moves to B, with domestic activity OD', gross domestic product $\mathrm{OC}^{\prime}$ and tariff revenue $\mathrm{EC}^{\prime}$. Assuming the nontraded good price remains at one (neglecting for simplicity the important general equilibrium linkage with the determination of the nontraded good price), the slope of the tangent at B is equal to the tariff distorted input price.

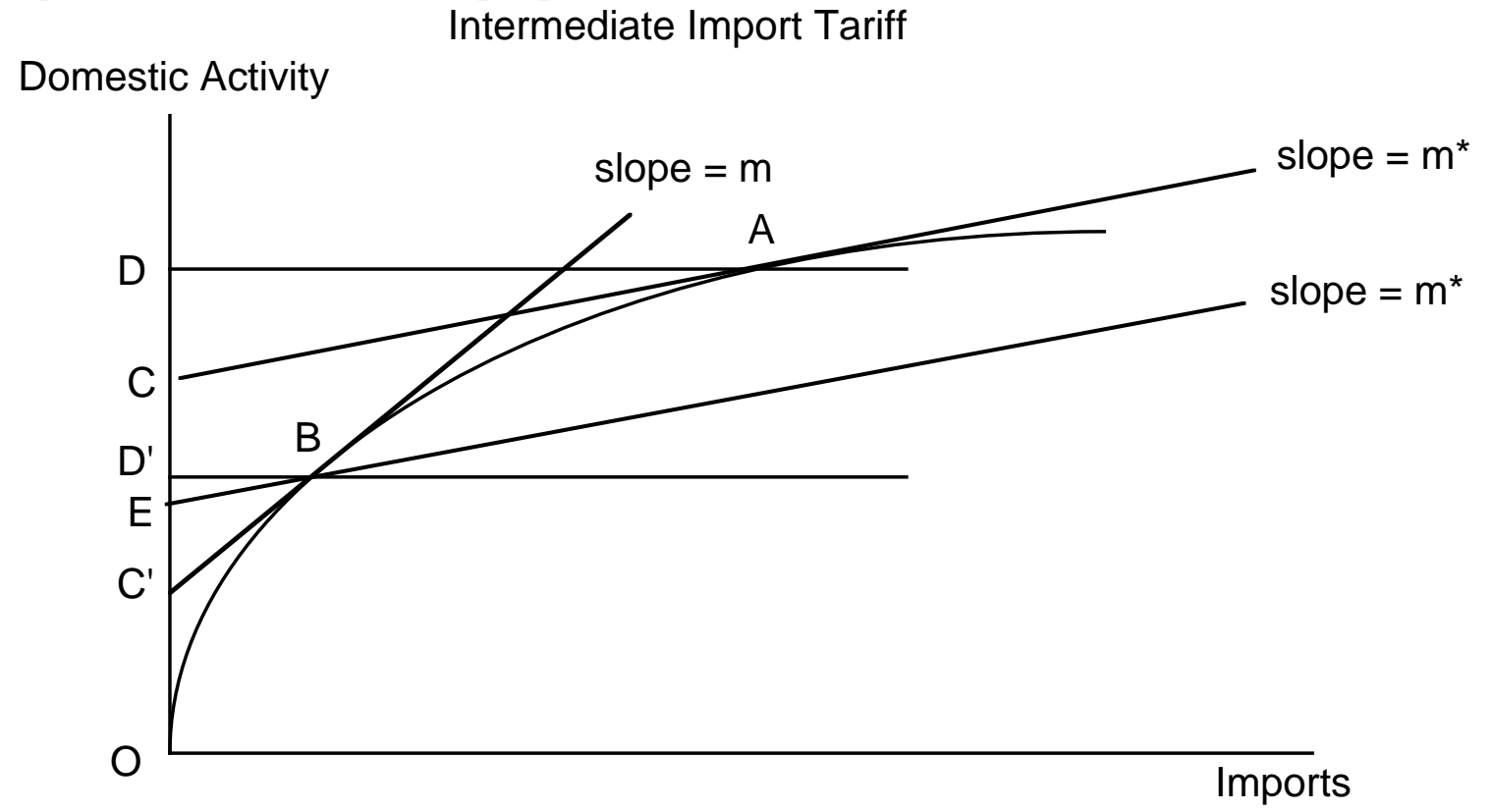

The elasticities of substitution in consumption, transformation and production control the curvature of the indifference curves, transformation functions and production functions respectively.

\section{A.1. CES Expenditure and Distorted Expenditure Functions}

The representative consumer is assumed to have a CES expenditure function of the form:
(A.1.1)$$
\mathrm{e}(\mathrm{h}, \mathrm{p}, \pi, \mathrm{u}) \quad=\quad\left(\alpha_{\mathrm{y}} \mathrm{h}^{1-\sigma^{*}}+\Sigma \beta_{\mathrm{k}} \mathrm{p}_{\mathrm{k}}^{1-\sigma^{*}}+\Sigma \alpha_{\mathrm{j}} \pi_{\mathrm{j}}^{1-\sigma^{*}}\right)^{\frac{1}{1-\sigma^{*}}} \mathrm{u},
$$ 
February 19, 1996

where $u$ is the level of utility, $p$ is the domestic price of quota-constrained goods, $\pi$ is the domestic price of non-quota-constrained goods, and $\mathrm{h}$ is the price of the non-traded good. The superscript $\mathrm{F}$ (for final goods) is omitted from $\mathrm{p}$ and $\pi$ for notational ease. The elasticity of substitution in demand is equal to the parameter $\sigma^{*}$, while the $\alpha$ 's and $\beta$ 's are share parameters for the non-quota constrained goods and the quota constrained goods respectively. The true cost of living index is

(A.1.2) $\quad \mathrm{P}=\left(\alpha_{\mathrm{y}} \mathrm{h}^{1-\sigma^{*}}+\Sigma \beta_{\mathrm{k}} \mathrm{p}_{\mathrm{k}}^{1-\sigma^{*}}+\Sigma \alpha_{\mathrm{j}} \pi_{\mathrm{j}}^{1-\sigma^{*}}\right)^{\frac{1}{1-\sigma^{*}}}$.

For empirical work, the benchmark year conventionally has prices all initially equal to one, and the $\alpha$ 's and $\beta$ 's are the initial expenditure share values in the data, and the initial level of expenditure is equal to $\mathrm{u}$.

The distorted expenditure function is built by imposing on (A.1.1) fixed binding quotas equal to $\mathrm{q}_{\mathrm{k}}$ for all $\mathrm{k}$. (The superscript $\mathrm{F}$ is again omitted for notational ease.) The distorted expenditure function is defined by (Anderson and Neary, 1992)

$$
\widetilde{\mathrm{e}}(\mathrm{h}, \mathrm{q}, \pi, \mathrm{u})=\max _{\mathrm{p}}\left\{\mathrm{e}(\mathrm{h}, \mathrm{p}, \pi, \mathrm{u})-\mathrm{p}^{\prime} \mathrm{q}\right\}
$$

The price vector $\mathrm{p}$ which solves this program is a virtual price vector, and with quotas it is also a market clearing price vector. Using Shephard's Lemma, and solving the first order (market clearing) condition for the (virtual and market) price of each quota constrained good k, we obtain for the CES case:

(A.1.3) $\quad \mathrm{p}_{\mathrm{k}}=\mathrm{P}\left(\frac{\mathrm{u} \beta \mathrm{k}}{\mathrm{qk}}\right)^{1 / \sigma^{*}}$

where $\mathrm{P}$ is the price index defined by equation (A.1.2). Substituting (A.1.2) into (A.1.3), the vector of virtual prices $\mathrm{p}$ is a implicitly defined as a function of the $\pi$ 's and the quotas. Fortunately, an explicit solution is available. First, substitute (A.1.3) into (A.1.2). Next, raise both right and left hand sides to the power $1-\sigma *$. Then, solve the resulting expression for $\mathrm{P}^{1-\sigma^{*}}$. Finally, raise both sides to the power $1 /(1-\sigma *)$. The reduced form true cost of living index is:
(A.1.4)
$\mathrm{P} \quad=\mathrm{P}(\mathrm{h}, \mathrm{q}, \pi, \mathrm{u})$ 
February 19, 1996

$$
=\left(\frac{\alpha_{\mathrm{y}} \mathrm{h}^{1-\sigma^{*}}+\Sigma \alpha_{\mathrm{j}} \pi_{\mathrm{j}}^{1-\sigma^{*}}}{1-\mathrm{u}^{\left(1-\sigma^{*}\right) / \sigma *} \Sigma \beta_{\mathrm{k}}^{1 / \sigma^{*}} \mathrm{q}_{\mathrm{k}}^{-\left(1-\sigma^{*}\right) / \sigma^{*}}}\right) 1 /\left(1-\sigma^{*}\right) .
$$

The connection of (A.1.4) to (A.1.2) is clear: if consumers face fixed price vector $p$ at the level of the virtual price vector $p$ defined by (A.1.3), their cost of living is the same as when constrained by quotas q.

The distorted expenditure function is obtained by substituting (A.1.3) and (A.1.4) into the definition of $\mathrm{e}$ :
(A.1.5)

$$
\widetilde{\mathrm{e}}(\mathrm{h}, \mathrm{q}, \pi, \mathrm{u})=\mathrm{P}(\pi, \mathrm{h}, \mathrm{q}, \mathrm{u}) \mathrm{u}-\mathrm{p}^{\prime} \mathrm{q},
$$

where $\mathrm{P}$ is given by (A.1.4) and $\mathrm{p}$ is given by (A.1.3). Equation (A.1.5) factors into:

$$
\begin{aligned}
& \widetilde{\mathrm{e}}(\mathrm{h}, \mathrm{q}, \pi, \mathrm{u}) \quad= \\
& \left(\alpha_{\mathrm{y}} \mathrm{h}^{1-\sigma^{*}+} \sum_{\mathrm{j}} \alpha_{\mathrm{j}} \pi_{\mathrm{j}}^{1-\sigma^{*}}\right)^{1 /\left(1-\sigma^{*}\right)}\left(1-\mathrm{u}^{\left(1-\sigma^{*}\right) / \sigma *} \Sigma \beta_{\mathrm{k}}^{1 / \sigma^{*}} \mathrm{q}_{\mathrm{k}}^{-\left(1-\sigma^{*}\right) / \sigma^{*}}\right)^{-\sigma^{*} /\left(1-\sigma^{*}\right)} \mathrm{u} .
\end{aligned}
$$

The constrained (by the presence of quotas) demand for unconstrained imports and for nontradables is obtained from use of Shephard's Lemma:
(A.1.7)

$$
\begin{array}{lll}
\widetilde{\mathrm{e}}_{\pi_{\mathrm{k}}} & =\alpha_{\mathrm{k}}\left(\frac{\pi_{\mathrm{k}}}{\mathrm{P}}\right)^{-\sigma^{*}} \mathrm{u} \\
\mathrm{e}_{\mathrm{h}} & =\alpha_{\mathrm{y}}\left(\frac{\mathrm{h}}{\mathrm{P}}\right)^{-\sigma^{*}} \mathrm{u} .
\end{array}
$$

The virtual price vector is obtained as:

$$
\text { (A.1.8) - } \mathrm{e}_{\mathrm{q}_{\mathrm{k}}}=\mathrm{p}_{\mathrm{k}}=\mathrm{e} \frac{\beta_{\mathrm{k}}^{1 / \sigma^{*}} \mathrm{u}_{0}^{\left(1-\sigma^{*}\right) / \sigma^{*}} \mathrm{q}_{\mathrm{k}}^{-1 / \sigma^{*}}}{1-\sum_{\mathrm{k}} \beta_{\mathrm{k}}^{1 / \sigma^{*}} \mathrm{u}_{0}^{\left(1-\sigma^{*}\right) / \sigma^{*}} \mathrm{q}_{\mathrm{k}}^{-\left(1-\sigma^{*}\right) / \sigma^{*}}} \text {. }
$$

\section{A.2. The CES/CET Cost and Product Functions}

Exports and the nontraded good are jointly produced with a CES/CET technology. The level of activity of the joint process is represented by $\mathrm{z}$, determined by the two outputs $\mathrm{y}$, the nontraded good, and $\mathrm{x}$, the export good.

\section{A. Total and Variable Cost Functions}

The cost of producing one unit of the activity $\mathrm{z}$ is equal to:
(A.2.1)
$\mathrm{c} \quad=\left(\Sigma \gamma_{\mathrm{j}} \mathrm{p}_{\mathrm{j}}^{1-\sigma}+\Sigma \gamma_{\mathrm{k}} \pi_{\mathrm{k}}^{1-\sigma}+\delta_{\mathrm{LW}}{ }^{1-\sigma}\right)^{1 /(1-\sigma)}$, 
February 19, 1996

where $\mathrm{p}$ is the price vector of imported intermediate inputs subject to quota, $\pi$ is the price vector of imported intermediate inputs not subject to quota and $w$ is the price of the nontraded factor ( the wage rate of labor). The superscript $M$ on $p$ and $\pi$ is omitted for notational ease. The $\gamma^{\prime}$ s and $\delta_{\mathrm{L}}$ are activity cost share parameters and $\sigma$ is the elasticity of technical substitution. Total cost is equal to cz. Nontraded intermediate goods are subsumed into the production and cost structure behind (A.2.1).

The total cost function under constraint yields the variable cost function. The input quotas are denoted $\mathrm{q}_{\mathrm{j}}$ for each good $\mathrm{j}$, with the superscript $\mathrm{M}$ being omitted for notational ease, and the nontraded factor is in fixed supply L. Shephard's Lemma and the market clearing equations can be used to solve for the prices of the nontraded and quota constrained inputs, just as the price of quota constrained final goods was obtained in equation (A.1.2). Thus the input demand

$$
\mathrm{q}_{\mathrm{j}} \quad=\gamma_{\mathrm{j}}\left(\frac{\mathrm{p}_{\mathrm{j}}}{\mathrm{c}}\right)-\sigma_{\mathrm{z}}
$$

implies a value of $\mathrm{p}_{\mathrm{j}}$ in terms of $\mathrm{c}$ and $\mathrm{z}$ :

$$
\mathrm{p}_{\mathrm{j}}=\mathrm{cz}^{1 / \sigma} \gamma_{\mathrm{j}}^{1 / \sigma} \mathrm{q}_{\mathrm{j}}^{-1 / \sigma} \text {. }
$$

The resulting solution for $\mathrm{p}_{\mathrm{j}}$ may be substituted into equation (A.2.1), and the equation solved first for $c^{1-\sigma}$ and then $c$ (the steps are the same as those leading from (A.1.2) to (A.1.4)) to obtain the reduced form unit cost function:

$$
\left.\begin{array}{l}
\mathrm{c}=\mathrm{C}(\mathrm{q}, \pi, \mathrm{L}, \mathrm{z})= \\
\left(\frac{\Sigma \gamma_{\mathrm{k}} \pi_{\mathrm{k}}^{1-\sigma}}{1-\mathrm{z}^{(1-\sigma) / \sigma}\left(\Sigma \gamma_{\mathrm{j}}^{1 / \sigma} \mathrm{q}_{\mathrm{j}}^{-(1-\sigma) / \sigma}+\delta_{\mathrm{L}}^{1 / \sigma} \mathrm{L}^{-(1-\sigma) / \sigma}\right)}\right)
\end{array}\right) .
$$

Note the similarity of (A.2.2) to (A.1.4). In the reduced form cost function it is convenient to define

$$
\mathrm{R}(\mathrm{q}, \mathrm{L}, \mathrm{z})=\mathrm{z}^{(1-\sigma) / \sigma}\left(\sum \gamma_{\mathrm{j}}^{1 / \sigma} \mathrm{q}_{\mathrm{j}}^{-(1-\sigma) / \sigma}+\delta_{\mathrm{L}}^{1 / \sigma} \mathrm{L}^{-(1-\sigma) / \sigma}\right)
$$

the share of total cost paid to fixed factors (the nontraded factor and the quota constrained inputs). To see how this interpretation arises, note that Shephard's Lemma implies that the share of cost paid to variable inputs is equal to $\Sigma \gamma_{\mathrm{k}} \pi_{\mathrm{k}}^{1-\sigma} / \mathrm{c}^{1-\sigma}$, where c is defined by 
February 19, 1996

(A.2.1). Now raise both sides of (A.2.2) to the power $1-\sigma$, multiply both sides by $1-\mathrm{R}$, and divide both sides by $\mathrm{c}^{1-\sigma}$. Then $\mathrm{R}$ is equal to $1-\Sigma \gamma_{\mathrm{k}} \pi_{\mathrm{k}}^{1-\sigma} / \mathrm{c}^{1-\sigma}$, which is the share of costs paid to fixed factors.

The variable cost function ${ }^{16}$ is obtained by using (A.2.2) and (A.2.3) with (A.2.1):
(A.2.4)
$\mathrm{V}=\operatorname{cz}(1-\mathrm{R})=\sum_{\mathrm{k}} \gamma_{\mathrm{k}} \mathrm{m}_{\mathrm{k}}^{1-\sigma} \mathrm{C}(.)^{\sigma_{\mathrm{Z}}}$

where $\mathrm{C}($.$) is given by (A.2.2). The variable cost function is more conveniently rewritten$ as:

$$
\mathrm{V}(\mathrm{q}, \pi, \mathrm{L}, \mathrm{z})=\left(\sum_{\mathrm{k}} \gamma_{\mathrm{k}} \pi_{\mathrm{k}}^{1-\sigma}\right)^{1 /(1-\sigma)}(1-\mathrm{R})^{-\sigma /(1-\sigma)} \mathrm{z},
$$

where $\mathrm{R}$ is given by (A.2.3). Note the similarity of form between (A.2.5) and (A.1.6).

The properties of the variable cost function are standard. Variable input demand is:

$$
\mathrm{V}_{\mathrm{k}}=\mathrm{C}_{\mathrm{k}}=\gamma_{\mathrm{k}} \mathrm{m}_{\mathrm{k}}^{-\sigma}\left(\sum_{\mathrm{k}} \gamma_{\mathrm{k}} \mathrm{m}_{\mathrm{k}}^{1-\sigma}\right)^{\sigma(1-\sigma)}(1-\mathrm{R})^{-\sigma /(1-\sigma)} \mathrm{z} \text {. }
$$

The marginal variable cost of competitive production is equal to $\mathrm{V}_{\mathrm{Z}}$, given by:

$$
\begin{aligned}
\mathrm{V}_{\mathrm{Z}} & =\frac{\mathrm{V}}{\mathrm{z}} \frac{1}{1-\mathrm{R}} \\
& =\left(\sum_{\mathrm{k}} \gamma_{\mathrm{k}} \pi_{\mathrm{k}}^{1-\sigma}\right)^{1 /(1-\sigma)}(1-\mathrm{R})^{-1 /(1-\sigma)} .
\end{aligned}
$$

Finally, the virtual and market price of the constrained input is

$$
-\mathrm{V}_{\mathrm{qj}}=\mathrm{p}_{\mathrm{j}}=\mathrm{z}^{(1-\sigma) / \sigma} \frac{\mathrm{V}}{1-\mathrm{R}} \gamma_{\mathrm{j}}^{1 / \sigma} \mathrm{q}_{\mathrm{j}}^{-1 / \sigma} \text {. }
$$

Equation (A.2.8) is the production analog to equation (A.1.8).

\section{B. Joint Product and Gross Domestic Product Functions}

For a given level of the activity $\mathrm{z}$, the profit maximizing decisions of producers select nontraded output $\mathrm{y}$ and export output $\mathrm{x}$ to maximize hy+ $\pi_{\mathrm{X}} \mathrm{x}$ subject to a constant elasticity of transformation production frontier $\mathrm{f}(\mathrm{x}, \mathrm{y}) \geq \mathrm{z}$. Here, $\pi_{\mathrm{x}}$ is the export price, the numeraire. The value of total output in this setup is equal to

$$
\phi\left(\mathrm{h}, \pi_{\mathrm{x}}\right) \mathrm{z}=\left((1-\mu) \pi_{\mathrm{x}}^{1+\theta}+\mu \mathrm{h}^{1+\theta}\right)^{1 /(1+\theta)} \mathrm{z},
$$

\footnotetext{
${ }^{16}$ Alternatively it could be termed the distorted variable cost function to emphasize that some of the fixed inputs are fixed by policy.
} 
where $\theta$ is the constant elasticity of transformation, $\partial \log (\mathrm{x} / \mathrm{y}) / \partial \log \left(\pi_{\mathrm{x}} / \mathrm{h}\right)$, and $\mu$ is a share parameter. Profit maximization implies that for given $\mathrm{z}$, nontraded output is equal to$$
\mathrm{y}=\phi_{\mathrm{h}} \mathrm{z}=\mu\left(\frac{\mathrm{h}}{\phi}\right)^{\theta} \mathrm{z} \text {. }
$$

The aggregate rent function is the supply side analog to the distorted expenditure function. It is a maximum value function equal to the sum of quota rents and payments to domestic fixed factors. Formally:$$
\tilde{g}\left(\mathrm{~h}, \mathrm{q}^{\mathrm{M}}, \pi^{\mathrm{M}}, \mathrm{L}\right)
$$$$
=\max _{\mathrm{z}}\left\{\phi(\mathrm{h}, 1) \mathrm{z}-\mathrm{V}\left(\mathrm{q}^{\mathrm{M}}, \pi^{\mathrm{M}}, \mathrm{L}, \mathrm{z}\right)\right\} .
$$

The first order condition of (A.2.11) can be solved for a closed form solution for the activity level z:

$$
\begin{aligned}
\mathrm{z} & =\left(\frac{1-\phi(\mathrm{h}, 1)^{\sigma-1} \sum_{\mathrm{k}} \gamma_{\mathrm{k}} \pi_{\mathrm{k}}^{1-\sigma}}{\Sigma \gamma_{\mathrm{j}}^{1 / \sigma} \mathrm{q}_{\mathrm{j}}^{-(1-\sigma) / \sigma}+\delta_{\mathrm{L}}^{1 / \sigma_{\mathrm{L}}(1-\sigma) / \sigma}}\right) \sigma /(1-\sigma) \\
= & \mathrm{z}\left(\mathrm{h}, \mathrm{q}^{\mathrm{M}}, \pi^{\mathrm{M}}, \mathrm{L}\right) .
\end{aligned}
$$

Here, $\phi$ is given by the right hand side of (A.2.9). Substituting (A.2.12) into the right hand side of (A.2.11) yields a closed form for $\widetilde{\mathrm{g}}$.

Gross domestic product is equal to the value of payments to domestic factors. This is written: 17

$$
\text { (A.2.13) } \mathrm{g}=\mathrm{g}-\mathrm{g} \mathrm{q}^{\prime} \mathrm{q}^{\mathrm{M}} \text {, }
$$

noting that $\widetilde{g}_{\mathrm{q}}=-\mathrm{V}_{\mathrm{q}}=\mathrm{p}^{\mathrm{M}}$, from the definition of (A.2.11) and of variable cost V. More conveniently for computations, $g$ is equal to $-\mathrm{LV}_{\mathrm{L}}\left(\mathrm{q}^{\mathrm{M}}, \pi^{\mathrm{M}}, \mathrm{L}, \mathrm{z}\right)$ where the $\mathrm{V}_{\mathrm{L}}=-\mathrm{w}$, the wage rate. The variable cost function has derivatives with respect to nontraded primary factors of the same form as (A.2.8). Thus $-\mathrm{LV}_{\mathrm{L}}$ is equal to

$$
\text { (A.2.13') } \frac{\mathrm{V}}{1-\mathrm{R}}\left(\delta_{\mathrm{L}}^{1 / \sigma} \mathrm{L}^{1-1 / \sigma}\right) \mathrm{z}^{1 / \sigma-1} \text {. }
$$

\footnotetext{
${ }^{17}$ It is important to note that the gross domestic product function in this setup is not an envelope function, due to the fact that the domestic value of $\mathrm{N}$ is lost. This imposes a terms of trade effect distortion relative to efficient production. The aggregate profit function$$
\Pi\left(\mathrm{p}_{\mathrm{X}}, \mathrm{h}, \mathrm{m}, \mathrm{N}, \mathrm{L}, \mathrm{K}\right)=\max \left\{\phi\left(\mathrm{p}_{\mathrm{X}}, \mathrm{h}\right) \mathrm{Z}-\mathrm{V}(\mathrm{m}, \mathrm{N}, \mathrm{L}, \mathrm{K}, \mathrm{Z})\right\} \text {. }
$$$$
\mathrm{Z}
$$

This has the envelope property $\prod_{h}=\mathrm{Y}=\phi_{\mathrm{h}} \mathrm{Z}$. 
February 19, 1996

Using (A.2.5) for $\mathrm{V}$, gross domestic product may be rewritten as

$$
\mathrm{g}\left(\mathrm{h}, \mathrm{q}^{\mathrm{M}}, \pi^{\mathrm{M}}, \mathrm{L}\right)=\left(\sum_{\mathrm{k}} \gamma_{\mathrm{k}}\left(\pi_{\mathrm{k}}^{\mathrm{M}}\right)^{1-\sigma}\right)^{1 /(1-\sigma)}(1-\mathrm{R})^{-1 /(1-\sigma)} \mathrm{z}^{1 / \sigma}\left(\delta_{\mathrm{L}}^{1 / \mathrm{L}^{1-1 / \sigma}}\right)
$$

Here, $\mathrm{R}$ is understood to be replaced by its value on the right hand side of (A.2.3) and $\mathrm{z}$ is replaced by its value on the right hand side of (A.2.12).

\section{A.3. General Equilibrium in the CES/CET Model}

General equilibrium is reached by clearance of the nontraded good market and by the balance of payments constraint, 2 equations to solve for the endogenous variables $h$ and u. As for the nontraded goods market,

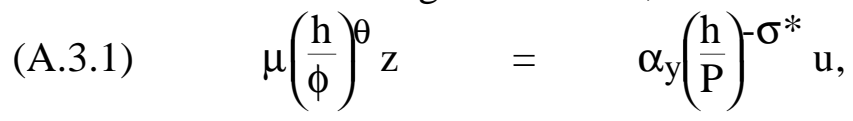

where $\mathrm{z}$ is defined by (A.2.12) and $\mathrm{P}$ is defined by (A.1.4). As for the balance of payments constraint,

$$
\begin{aligned}
& \widetilde{e}\left(\mathrm{~h}, \mathrm{q}^{\mathrm{F}}, \pi^{\mathrm{F}}, \mathrm{u}\right)-\widetilde{\mathrm{e}}_{\mathrm{q}}(.)^{\prime} \mathrm{q}^{\mathrm{F}}-\left(\widetilde{g}-\widetilde{g}_{\left.\mathrm{q}^{\prime} \mathrm{q}^{\mathrm{M}}\right)}\right. \\
& -\left(\pi^{\mathrm{F}}-\pi^{\mathrm{F} *}\right)^{\prime} \mathrm{e}_{\pi}(.)-\left(\pi^{\mathrm{M}}-\pi^{\mathrm{M} *}\right)^{\prime}\left(-\widetilde{\mathrm{g}}_{\pi}\right) \quad-\mathrm{t}^{\mathrm{q}} \mathrm{q}=\beta \text {, }
\end{aligned}
$$

where $\beta$ is a parametric trade deficit or surplus. The first line gives the difference between expenditure at domestic prices and payments to labor. The second line gives minus the sum of tariff revenue. In this setup, all rent other than that retained by $\mathfrak{A}^{\prime} \mathrm{q}$ is lost. Equation system (A.3.1)-(A.3.2) is solved for $\mathrm{h}$ and $\mathrm{u}$.

The TRI is solved as follows. Hold u constant, deflate 'new' prices of distorted goods by $\Delta$ as defined in the text equations (1)-(5), and solve (A.3.1)-(A.3.2) for $\mathrm{h}$ and $\Delta$. In the text, the implicit solution for $\mathrm{h}$ is understood to be substituted into the various functions in (A.3.2) throughout. 


\section{References}

Anderson, James E., Geoffrey Bannister and J. Peter Neary (1995), "Domestic Distortions and International Trade", International Economic Review, .

Anderson, James E.. and J. Peter Neary (1992), "Trade reform with quotas, partial rent retention and tariffs", Econometrica, $\underline{60}$, 57-76.

Anderson, James E. and J. Peter Neary (1994), "The Trade Restrictiveness of the MultiFibre Arrangement", World Bank Economic Review, Anderson, James E. and J. Peter Neary (1994), "A New Approach to Evaluating Trade Policy".

Edwards, Sebastian (1993), "Openness, Trade Liberalization and Growth in Developing Countries", Journal of Economic Literature, 31, 1358-1393. 